\title{
Erratum to: The Humanities in Contemporary Chinese Contexts
}

\author{
Evelyn T.Y. Chan and Michael O'Sullivan
}

\section{Erratum to:}

\section{E.T.Y. Chan and M. O'Sullivan (eds.),}

The Humanities in Contemporary Chinese Contexts, The Humanities in Asia 2, DOI 10.1007/978-981-10-2267-8

In the book frontmatter, Contributors were newly added and in Chapter 6 the author biographies were removed.

The updated original online version for this book can be found at DOI 10.1007/978-981-10-2267-8_6

E.T.Y. Chan $(\bowtie) \cdot$ M. O'Sullivan $(\bowtie)$

Department of English, The Chinese University of Hong Kong,

Hong Kong, Hong Kong

e-mail: evelyn_chan@cuhk.edu.hk

M. O'Sullivan

e-mail: osullivan@cuhk.edu.hk 